\title{
BMP-9 is a novel marker for colorectal tumorigenesis undergoing the normal mucosa-adenoma-adenocarcinoma sequence and is associated with colorectal cancer prognosis
}

\author{
YINJIE FAN $^{1}$, LINGXIANG GUO ${ }^{1}$, HUACHUAN ZHENG ${ }^{2}$, CHUNYONG JI $^{1}$, \\ WENBIN WANG ${ }^{3}$ and HONGZHI SUN ${ }^{3,4}$
}

\begin{abstract}
${ }^{1}$ Department of General Surgery, The Affiliated Zhengzhou Central Hospital of Zhengzhou University, Zhengzhou, Henan 450007; ${ }^{2}$ Department of Experimental Oncology and Animal Center, Shengjing Hospital of China Medical University, Shenyang, Liaoning 110004; ${ }^{3}$ Department of Surgery, The First Affiliated Hospital of Jinzhou Medical University; ${ }^{4}$ Key Laboratory of Tumor Clinical Metabolomics, The First Affiliated Hospital of Jinzhou Medical University, Jinzhou, Liaoning 121001, P.R. China
\end{abstract}

Received January 30, 2019; Accepted October 10, 2019

DOI: $10.3892 / 01.2019 .11125$

\begin{abstract}
Depending on the type of cancer, bone morphogenetic protein-9 (BMP-9) can promote or inhibit tumorigenesis; however, the function of BMP-9 in colorectal cancer remains unclear. The aim of the present study was to evaluate the clinicopathological importance of BMP-9 expression in the tumorigenesis of normal colorectal epithelial tissue, and subsequent transformation into adenoma and carcinoma. In addition, the present study aimed to determine the prognostic value of BMP-9 on the survival of patients with colorectal cancer (CRC). A total of 65 patients with pathologically confirmed colorectal adenocarcinoma and a history of adenoma were enrolled. BMP-9 and Ki-67 expression was assessed retrospectively using paraffin-embedded samples of normal colorectal mucosa, colorectal adenoma and CRC obtained from each patient. The prognostic value of BMP-9 expression was analyzed in a group comprising 48 patients with CRC and a mean follow-up duration of 39.1 months. Bioinformatics analyses were performed in order to validate the results of the present study using published CRC datasets. The results from the present study suggested that the expression of BMP-9 gradually increased during the transition from normal mucosa to adenoma and subsequent adenocarcinoma $(\mathrm{P}<0.05)$; however, no significant association between the expression levels of BMP-9 and the clinicopathological parameters of patients was reported. Kaplan-Meier analysis revealed that patients
\end{abstract}

Correspondence to: Professor Hongzhi Sun, Key Laboratory of Tumor Clinical Metabolomics, The First Affiliated Hospital of Jinzhou Medical University, 5-2 Ren'min Street, Jinzhou, Liaoning 121001, P.R. China

E-mail: crmhongzhi_sun@163.com

Key words: bone morphogenetic protein-9, colorectal cancer, tumorigenesis, survival with high expression levels of BMP-9 exhibited shorter overall survival rate than those with low levels of expression (54.7 vs. 41.3 months; log-rank test, $\mathrm{P}<0.05)$. Furthermore, regardless of tumor location and the presence of blood vessel tumor emboli, the univariate and multivariate analyses indicated that BMP-9 expression may be an independent prognostic factor for the overall survival rate of patients with CRC. The results of the present study suggested that BMP-9 may serve an oncogenic role and possess prognostic value in CRC.

\section{Introduction}

At present, colorectal cancer (CRC) is the third most common malignancy in males and the second in females worldwide $(1,2)$. Due to the high mortality rate, primarily as a result of occult or clinically overt metastases present at the time of diagnosis, and increased understanding of the molecular mechanisms underlying the malignant transformation of normal colorectal epithelial cells in the progression of adenoma to adenocarcinoma is required (3). Colorectal tumorigenesis is a complex process mediated by a number of genes and various signaling pathways, which ultimately results in the robust growth of transformed cells $(4,5)$. Despite notable progress in the current understanding of the mechanisms underlying this process, the aggressive nature and increased degree of metastasis of certain types of CRC requires further investigation. From a clinical perspective, improved understanding of these differences may aid the identification of prognostic biomarkers for $\mathrm{CRC}$, consequently facilitating the personalized management of CRC to improve the prognosis of patients with this disease.

Bone morphogenetic proteins (BMPs) are members of the transforming growth factor- $\beta$ (TGF- $\beta$ ) family, which are multi-functional cytokines (6). BMPs are divided into several subgroups, including the BMP-2/4, BMP-5/6/7/8 and BMP-9/10 groups, and the growth differentiation factor (GDF)-5/6/7 group, depending on their structural similarities and ability to bind certain type I receptors (7). Of note, 20 BMPs have been reported to possess a number of functions that 
regulate different physiological processes, including cellular proliferation, differentiation, migration and apoptosis $(8,9)$. BMP-9, also known as GDF-2, is a potent BMP member of the TGF- $\beta$ family (10). Previous studies have demonstrated that BMP-9 acts as a multifunctional mediator in numerous biological processes, including the regulation of cell proliferation, differentiation, adhesion, migration and apoptosis (11-13). These processes are involved in bone morphogenesis, hepatic reticuloendothelial system function, neuronal differentiation, hematopoiesis, angiogenesis, and iron and glucose homeostasis (10,14-19).

Accumulating evidence has demonstrated that BMP-9 is involved in tumorigenesis, and its expression varies according to tumor types. For example, compared with normal thyroid tissues, BMP-9 expression in thyroid tumors is increased (20). In addition, $\sim 25 \%$ of ovarian cancers exhibit upregulated BMP-9, which has been associated with the tumorigenesis and progression of the disease (21). BMP-9 promotes the growth of hepatocellular carcinoma cells, but not that of immortalized human hepatocytes (22). Furthermore, BMP-9 enhances the invasiveness of hepatocellular carcinoma cells by inducing the epithelial-to-mesenchymal transition (23). Conversely, BMP-9 was demonstrated to act as an apoptotic regulator, suppressing tumor growth in prostate cancer and myeloma (24,25). BMP-9 inhibits the proliferation, invasion and metastasis of breast cancer cells (26-28).

Due to its complex function, the ambiguous roles of BMP-9 as a tumor-promoting and tumor-suppressive factor require further investigation. Furthermore, the role of BMP-9 in colorectal tumorigenesis remains to be elucidated. The present study aimed to evaluate the prognostic value of BMP-9 expression in colorectal carcinoma, and to determine the association between the clinicopathological parameters of CRC and the prognostic potential of BMP-9 in patients with this disease.

\section{Materials and methods}

Ethics statement. The present study was performed in accordance with the Declaration of Helsinki and approved by the Ethics Committee of The First Affiliated Hospital of Jinzhou Medical University. The Ethics Committee waived the need for written informed consent from the patients due to the retrospective nature of the present study. Each tissue sample and respective clinical data was anonymized and no additional patient intervention was performed.

Clinical samples. A total of 65 patients with pathologically confirmed colorectal adenocarcinoma and a history of adenoma were enrolled in the present study; patients were surgically treated in The First Affiliated Hospital of Jinzhou Medical University (Jinzhou, China) between April 2012 and December 2014. The mean age of the 56 patients was 65 years (range, 47-84 years), and there were 47 men and 18 women. The inclusion criteria were as follows: i) Pathologically diagnosed with colorectal adenocarcinoma and a history of adenoma; ii) no previous neoadjuvant radiotherapy or chemotherapy treatment; and iii) no surgery for colorectal diseases. The exclusion criteria were as follows: i) Patients with other malignant tumors; ii) patients with severe organ dysfunction; and iii) patients with other types of colorectal diseases. The tissues obtained were fixed in $10 \%$ formaldehyde in PBS for $24 \mathrm{~h}$ at room temperature, and embedded in paraffin. For each patient, three paraffin-embedded tissue blocks were analyzed, comprising normal mucosa, adenoma and adenocarcinoma. All 195 tissue blocks were obtained from the Department of Pathology at The First Affiliated Hospital of Jinzhou Medical University. Pathological reports and the clinical history of patients were obtained from medical records. Follow-up information was available for 48 patients $(73.85 \%)$. The patient demographics and the clinicopathological features of the specimens are summarized in Table I.

Pathological examination and laboratory analysis. The Tumor-Node-Metastasis (TNM) staging and histological type of patient samples were primarily determined according to the 7th edition of the American Joint Committee's Cancer Staging Manual (29,30). Dukes stages (A, B, C and D) were classified according to cancer invasion, lymph node metastasis and distant metastasis, referring to the Dukes staging of Colorectal Cancer (1984) (31).

In order to measure the levels of CEA and CA19-9, blood samples from 52 patients $(80 \%)$ and 44 patients $(67.69 \%)$, respectively, were obtained 2-3 days prior to surgery. Peripheral blood was centrifuged at $1,800 \mathrm{x}$ g for $20 \mathrm{~min}$ at $4^{\circ} \mathrm{C}$ to obtain serum. The levels of these markers in the serum were measured using an i2000 automatic immunoluminescence analyzer (Abbott Laboratories). Serum levels of carcinoembryonic antigen (CEA) $>3.4 \mathrm{ng} / \mathrm{ml}$ and CA 19-9 >27 U/ml were considered abnormal.

Immunohistochemistry (IHC). Formalin-fixed paraffinembedded tissue blocks from the 65 patients, including colorectal mucosa, adenoma and adenocarcinoma specimens, were cut into $4 \mu \mathrm{m}$-thick sections and affixed to glass slides. Sections were deparaffinized in xylene, rehydrated via a descending alcohol series in double distilled water (including $100,80,70,50$ and $30 \%$ alcohol) for 2 min per concentration, and then rinsed in distilled water at room temperature. The antigen retrieval process performed was specific to each marker. For BMP-9, the slides were immersed in citrate buffer (10 mmol/l citric acid and sodium citrate; $\mathrm{pH}$ 6.0) and heated in a pressure cooker for $10 \mathrm{~min}$ at $100^{\circ} \mathrm{C}$. In the case of $\mathrm{Ki}-67$, the slides were boiled in citrate buffer $(10 \mathrm{mmol} / \mathrm{l}$ citric acid and sodium citrate; $\mathrm{pH}$ of 6.0 ) at $100^{\circ} \mathrm{C}$ in a microwave oven for $20 \mathrm{~min}$. The slides were allowed to cool at room temperature for $60 \mathrm{~min}$ and were then blocked with $1 \%$ bovine serum albumin in TBS (Sigma-Aldrich; Merck KGaA) for $60 \mathrm{~min}$ at room temperature. Staining was performed in a humidified chamber overnight at $4^{\circ} \mathrm{C}$ using the following antibodies (both from Abcam): Anti-BMP-9 (1:100; cat. no. ab35088) and anti-Ki-67 (1:250; cat. no. ab15580). Following incubation with primary antibodies, endogenous peroxidase activity was blocked by incubating the slides with $3 \%$ hydrogen peroxide for $10 \mathrm{~min}$ at room temperature. The sections were subsequently stained using the two-step plus ${ }^{\circledR}$ Poly-HRP Anti-Mouse/Rabbit IgG Detection System (cat. no. PV-9000; OriGene Technologies, Inc) for $20 \mathrm{~min}$ at room temperature. BMP-9 and Ki-67 expression was visualized via staining with 3,3'-diaminobenzidine (Sigma-Aldrich; Merck KGaA) for 5 and $2 \mathrm{~min}$ at room temperature, respectively. The nuclei were 
Table I. Clinical and demographic characteristics of patients enrolled in the present study.

\begin{tabular}{|c|c|}
\hline Characteristics & $\mathrm{n}(\%)$ \\
\hline \multicolumn{2}{|l|}{ Sex } \\
\hline Male & $47 / 65(72.3)$ \\
\hline Female & $18 / 65(27.7)$ \\
\hline \multicolumn{2}{|l|}{ Age, years } \\
\hline$\leq 55$ & $11 / 65(16.9)$ \\
\hline$>55$ & $54 / 65(83.1)$ \\
\hline \multicolumn{2}{|l|}{ Tumor site } \\
\hline Rectum & $39 / 65(60.0)$ \\
\hline Left-side colon & $17 / 65(26.2)$ \\
\hline Right-side colon & $9 / 65(13.8)$ \\
\hline \multicolumn{2}{|l|}{ Gross tumor type } \\
\hline Ulcerative & $49 / 65(75.4)$ \\
\hline Elevated & $16 / 65(24.6)$ \\
\hline \multicolumn{2}{|c|}{ Tumor differentiation } \\
\hline Poor & $6 / 65(9.2)$ \\
\hline Moderate & $54 / 65(83.1)$ \\
\hline High & $5 / 65(7.7)$ \\
\hline \multicolumn{2}{|c|}{ Tumor histological type } \\
\hline Tubular papillary & $16 / 65(24.6)$ \\
\hline Tubular & $44 / 65(67.7)$ \\
\hline Mucinous & $5 / 65(7.7)$ \\
\hline \multicolumn{2}{|c|}{ Tumor WHO classification } \\
\hline Low & $53 / 65(81.5)$ \\
\hline High & $12 / 65(18.5)$ \\
\hline \multicolumn{2}{|c|}{ Blood vessel tumor embolus } \\
\hline Positive & $7 / 65(10.8)$ \\
\hline Negative & $58 / 65(89.2)$ \\
\hline \multicolumn{2}{|l|}{ TNM stage } \\
\hline I-II & $46 / 65(70.8)$ \\
\hline III-IV & $19 / 65(29.2)$ \\
\hline \multicolumn{2}{|l|}{ Serum CEA levels } \\
\hline High & $22 / 52(42.3)$ \\
\hline Normal & $30 / 52(57.7)$ \\
\hline \multicolumn{2}{|c|}{ Serum CA19-9 levels } \\
\hline High & 9/44 (20.5) \\
\hline Normal & $35 / 44(79.5)$ \\
\hline \multicolumn{2}{|l|}{ Adenomas site } \\
\hline Left-side colon & $14 / 65(21.5)$ \\
\hline Right-side colon & $11 / 65(16.9)$ \\
\hline Rectum & $40 / 65(61.6)$ \\
\hline \multicolumn{2}{|c|}{ Number of adenomas } \\
\hline Single & $56 / 65(86.2)$ \\
\hline Multiple & 9/65 (13.8) \\
\hline \multicolumn{2}{|c|}{ Adenomas histological type } \\
\hline Tubular & $41 / 65(63.1)$ \\
\hline Tubulovillous & $24 / 65(36.9)$ \\
\hline \multicolumn{2}{|l|}{ Adenoma dysplasia } \\
\hline Mild & $29 / 65(44.6)$ \\
\hline Moderate & $27 / 65(41.5)$ \\
\hline Severe & 9/65 (13.9) \\
\hline
\end{tabular}

TNM, Tumor-Node-Metastasis; CEA, carcinoembryonic antigen, CA19-9, carbohydrate antigen 19-9; WHO, World Health Organization. counterstained with hematoxylin for 8 min (Sigma-Aldrich; Merck KGaA) at room temperature. The slides were dehydrated via an alcohol gradient, including 100, 70, 50 and 30\% alcohol, in double distilled water for 1 min each time and then immersed in xylene. Subsequently, the slides were fixed with Histomount mounting medium (cat. no. HS-103-100ML; AGTC Bioproducts Ltd.)

Evaluation of staining. All immunostained sections were evaluated semi-quantitatively under an Olympus BX40 light microscope (Olympus Corporation; magnification, $\mathrm{x} 400$ ) by two investigators from the The First Affiliated Hospital of Jinzhou Medical University (Jinzhou, Liaoning) who were blinded to the clinicopathological data. In the case of discrepancies between the evaluators, a consensus was reached after obtaining a third and final opinion from the director of the Department of Pathology at The First Affiliated Hospital of Jinzhou Medical University. BMP-9 expression was calculated as the product of the relative score, reflecting the percentage of positively stained cells $(0,<5 \% ; 1,5-25 \% ; 2,25-50 \% ; 3,50-75 \%$; and $4,>75 \%)$, and the intensity of the staining ( 0 , negative; 1, weak; 2, moderate; and 3, strong). The final BMP-9 expression score ranged from 0-12, and was subsequently classified into 4 levels: '-' for negative (0), ' + ' for mild (1-3), '++' for moderate (4-7) and ' +++ ' for strong (8-12). For the assessment of Ki-67 expression, cells with positive nuclear staining were counted and the percentage of positively stained cells was calculated as aforementioned. The staining was assessed as '-' (negative, $<5 \%$ ), ' + ' (moderately positive, $5-25 \%$ ), ' ++ ' (positive, $25-50 \%$ ) and '+++' (strongly positive, $>50 \%$ ).

Bioinformatics analysis. To further analyze the role of BMP-9 in CRC, the expression of BMP-9 and the clinicopathological data of patients were extracted from The Cancer Genome Atlas (TCGA) (https://cancergenome.nih.gov/). Additionally, the Kurashina (GSE11417) (32) and Gaedcke (GSE20842) (33) dataset from the Oncomine database (https://www.oncomine. org/), which is a cancer microarray database and web-based data-mining platform for genome-wide expression analyses, was downloaded. The data employed were used to compare differences in BMP-9 expression at the mRNA level between healthy colorectal tissue and tumor tissues. In addition, the correlation between BMP-9 expression, and the clinicopathological and prognostic data of patients with CRC was determined. All data were log-transformed, median-centered per array and standard deviation-normalized to one per array.

Statistical analysis. The expression of BMP-9 in colorectal tumorigenesis and the associations between the clinicopathological features and the status of BMP-9 expression were assessed via Spearman's rank correlation analysis. A Kaplan-Meier analysis was performed in order to estimate the 5-year overall survival (OS) rate for patients with CRC with low- or high- BMP-9 expression levels. These expression groups were defined according to the mean IHC score (2.17); IHC scores $0-2$ were considered to indicate low-BMP-9 expression, while a score of $\geq 3$ was recorded as high BMP-9 expression. Differences between groups were analyzed with a log-rank test. Significant factors from univariate analyses were included in the multivariate models. A Cox proportional 
Table II. BMP-9 expression in colorectal carcinoma, adenoma and normal colorectal mucosa.

\begin{tabular}{|c|c|c|c|c|c|}
\hline \multirow[b]{2}{*}{ Tissue type } & \multicolumn{4}{|c|}{ BMP-9 expression, n (\%) } & \multirow[b]{2}{*}{$\operatorname{PR}(\%)$} \\
\hline & - & + & ++ & +++ & \\
\hline Normal colorectal mucosa & $21(32)$ & $42(65)$ & $2(3)$ & $0(0)$ & 68 \\
\hline Colorectal adenoma & $6(9)$ & $20(31)$ & $22(34)$ & $17(26)$ & 91 \\
\hline Colorectal carcinoma & $3(5)$ & $8(12)$ & $29(45)$ & $25(38)$ & 95 \\
\hline
\end{tabular}

BMP-9, bone morphogenetic protein-9; PR, positive rate.

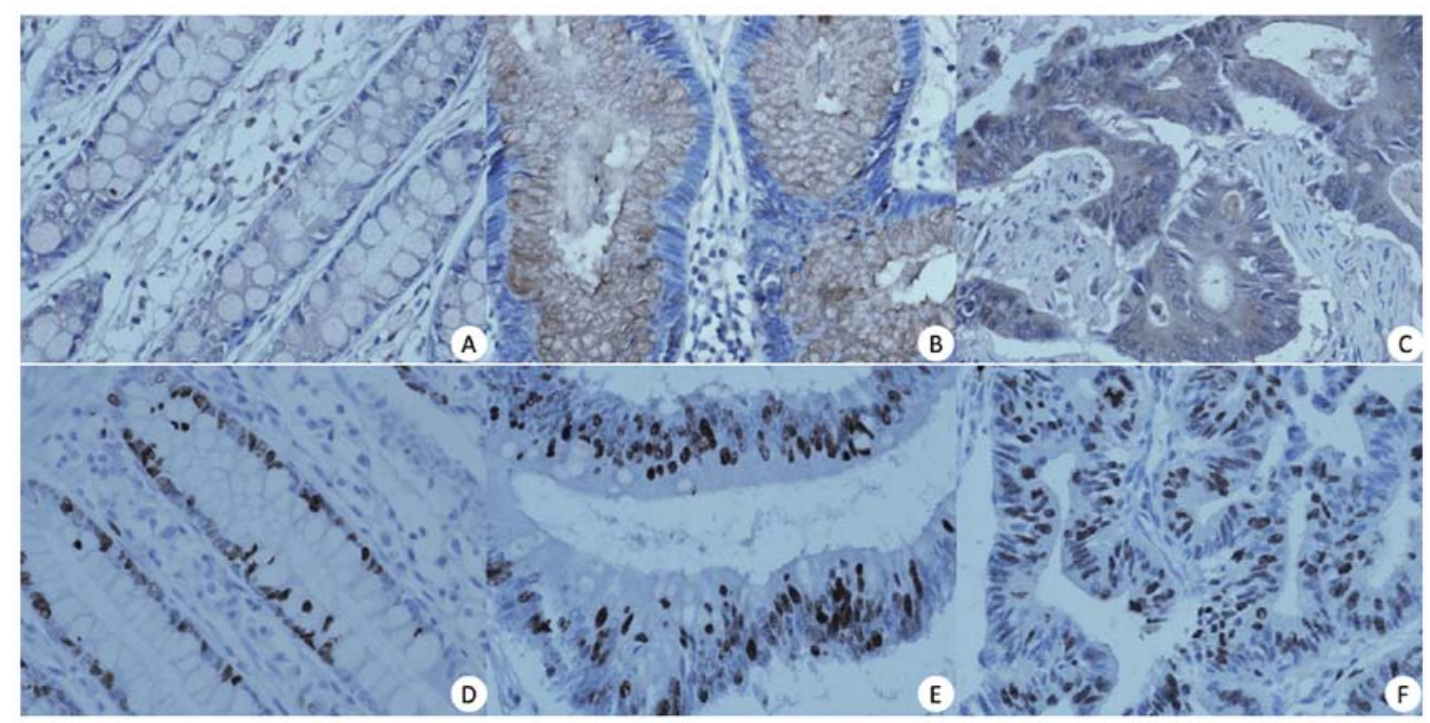

Figure 1. Bone morphogenetic protein-9 expression in (A) normal colorectal mucosa; (B) colorectal adenoma; and (C) carcinoma. Ki-67 expression in (D) normal colorectal mucosa, (E) colorectal adenoma and (F) carcinoma in a series of tissue samples obtained from the same patient (magnification, $\mathrm{x} 400$ ).

hazards model was used to perform multivariate survival analyses in order to identify independent prognostic factors. For the bioinformatics analysis, the BMP-9 expression levels in different colorectal tissues were compared using a repeated measures ANOVA. The comparison of data from multiple groups against a single control group was performed using a Dunnett's post hoc test. The comparison of data from multiple groups against every other group was performed using a Tukey's multiple comparisons test. $\mathrm{P}<0.05$ was considered to indicate a statistically significant difference. All statistical analyses were conducted using SPSS software (version 20; IBM Corp.) and GraphPad Prism software (version 7.0; GraphPad Software Inc.).

\section{Results}

Expression of BMP-9 in CRC. In order to investigate the role of BMP-9 in colorectal tumorigenesis, the present study assessed BMP-9 expression in normal mucosa, adenoma and colorectal carcinoma samples using IHC staining. In normal colorectal mucosa, decreased BMP-9 expression was detected in the cell membrane and cytoplasm of colorectal mucosal cells; in the majority of cases $(60 / 65,92.31 \%)$, the protein was not present in the nucleus (Fig. 1A). In colorectal adenoma tissues, BMP-9 was moderately expressed in the membrane and/or cytoplasm at a level similar to that in normal tissues. In addition, BMP-9 expression was undetectable in the nucleus in the majority of cases $(62 / 65,95.38 \%$ ) (Fig. 1B). On the contrary, in carcinoma tissues, BMP-9 was strongly expressed and predominantly observed in the membrane and/or cytoplasm of cancer cells, but was weakly expressed or undetectable in the nucleus (Fig. 1C; Table II). The positive rates of BMP-9 expression in normal colorectal mucosa, adenoma and carcinoma tissues were 68, 91 and 95\%, respectively (Table II). The expression levels of BMP-9 presented an upward trend in the aforementioned tissues, with mean values of $0.7,1.8$ and 2.2 , respectively. The elevated BMP-9 expression levels of the three types of tissue were statistically significant $\left(r^{2}=0.615\right.$; $\mathrm{P}<0.05)$. Furthermore, BMP-9 expression was significantly upregulated in carcinoma samples when compared with adenoma samples $\left(r^{2}=0.221 ; \mathrm{P}<0.05\right)$ (Table II). Similarly, significantly increased BMP-9 expression was observed in adenoma tissues compared with normal mucosa $\left(r^{2}=0.572\right.$; $\mathrm{P}<0.05)$. In the TCGA and Gaedcke and Kurashina datasets, BMP-9 mRNA expression was significantly increased in CRC tissues compared with healthy tissues $(\mathrm{P}<0.05$; Fig. 2A-C).

Correlation between BMP-9 expression and tumor cell proliferation in human CRC. In order to examine the correlation between BMP-9 expression and cell proliferation, the expression 
A

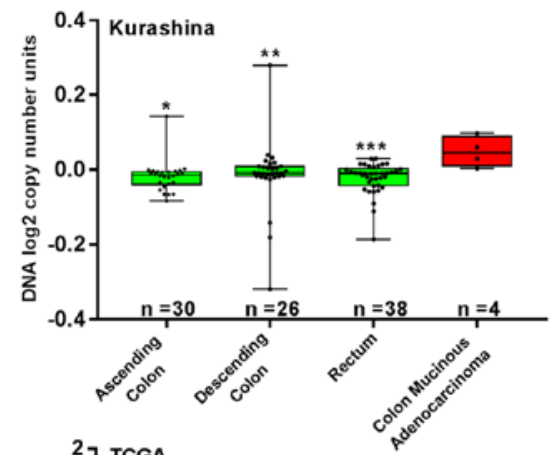

\author{
C
}
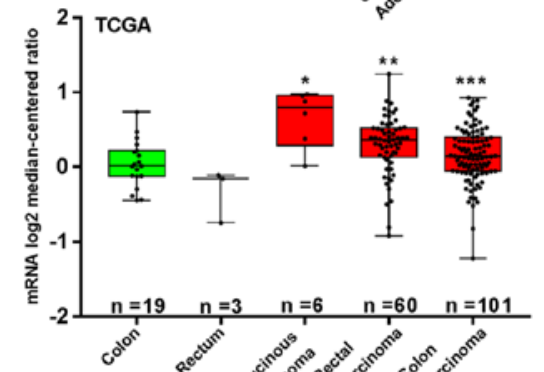

E
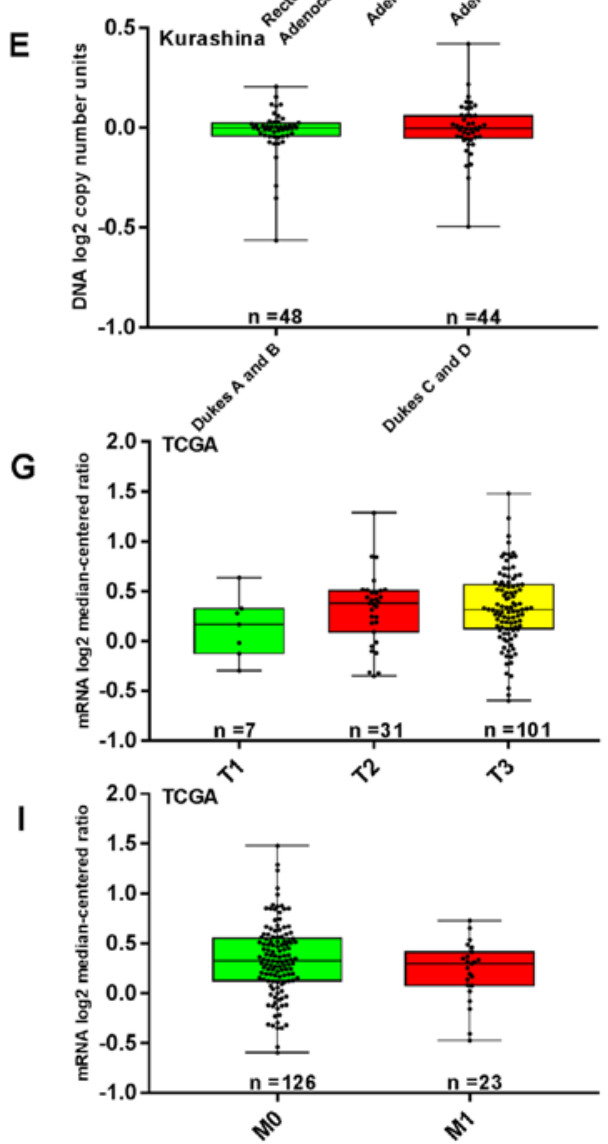

B

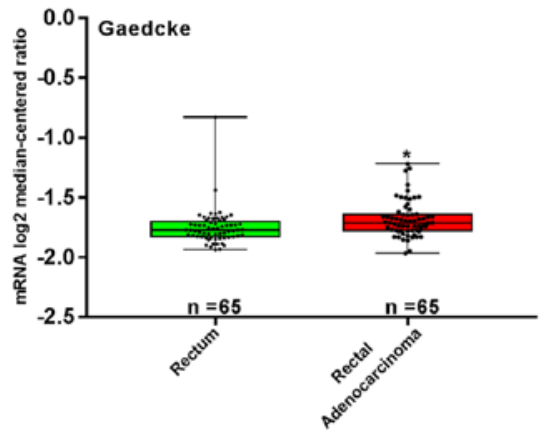

D

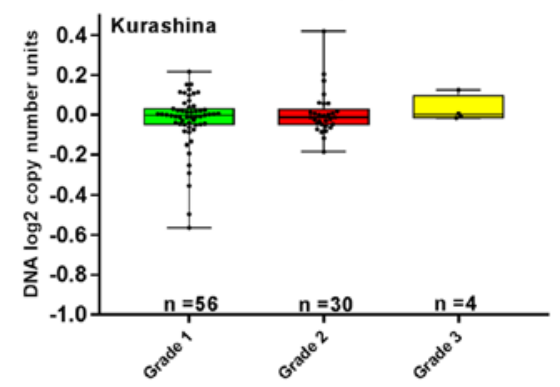

F

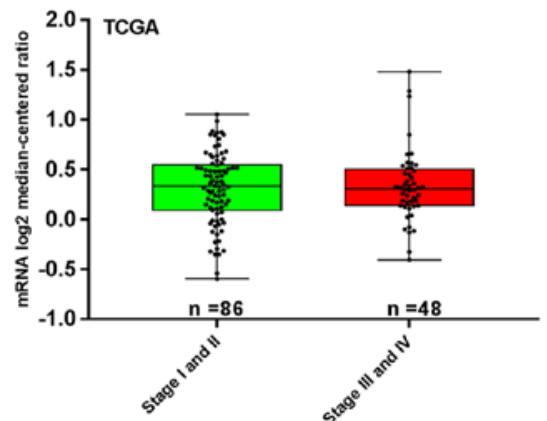

H

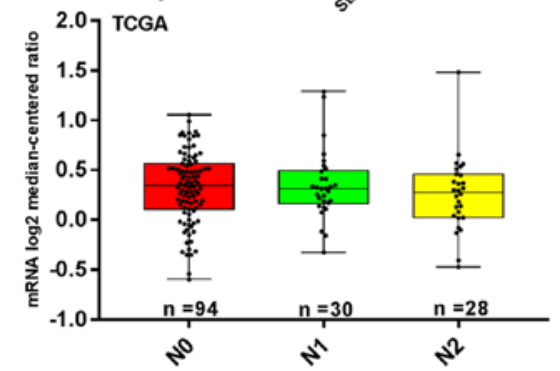

Figure 2. Association between the clinicopathological parameters of CRC and BMP-9 expression. TCGA (mRNA), Kurashina (DNA) and Gaedcke (mRNA) datasets were utilized for the bioinformatics analysis to investigate BMP-9 expression in colorectal carcinogenesis. (A) Increased BMP-9 expression was detected in CRC tissue compared with normal colorectal mucosa in the Kurashina dataset. ${ }^{*} \mathrm{P}<0.001,{ }^{* * *} \mathrm{P}<0.05,{ }^{* * * *} \mathrm{P}<0.01$ vs. colon mucinous adenocarcinoma. (B) Analysis of the Gaedcke dataset indicated that BMP-9 expression in rectal adenocarcinoma was increased compared with normal rectal mucosa ( $\mathrm{P}<0.001)$. (C) BMP-9 expression was significantly upregulated in CRC tissue compared with normal colorectal mucosa in the TCGA dataset. ${ }^{*} \mathrm{P}<0.001,{ }^{* * *} \mathrm{P}<0.01,{ }^{* * * *} \mathrm{P}<0.05$ vs. colon and rectum. From the Kurashina dataset, BMP-9 expression was determined to not be associated with (D) grade classifications and (E) Dukes staging of CRC (P>0.05). (F-I) Analysis of the dataset of TCGA revealed that BMP-9 mRNA expression were not associated with the TNM stages of CRC (P >0.05). BMP-9, bone morphogenetic protein-9; CRC, colorectal cancer; TCGA, The Cancer Genome Atlas; T, Tumor; N, Node; M, metastasis.

of Ki-67 in the same sample set was evaluated by IHC. In normal mucosa, cells positive for nuclear Ki-67 were localized primarily at the bottom of the glands, whereas, in adenoma and carcinoma samples, such cells were distributed randomly (Fig. 1D-F). The mean Ki-67 indices were significantly higher in adenoma and carcinoma compared with normal tissues (2.4, 
Table III. Ki-67 expression in colorectal carcinoma, adenoma and normal colorectal mucosa.

\begin{tabular}{lcccrrrr}
\hline & \multicolumn{4}{c}{ Ki-67 expression, $\mathrm{n}(\%)$} \\
\cline { 2 - 5 } Tissue type & - & + & ++ & +++ & PR (\%) & $\mathrm{r}^{2}$-value & P-value \\
\hline Normal colorectal mucosa & $12(18)$ & $24(37)$ & $22(34)$ & $7(11)$ & 82 & 0.711 & $\mathrm{P}<0.001$ \\
Colorectal adenoma & $0(0)$ & $6(9)$ & $27(42)$ & $32(49)$ & 100 & \\
Colorectal carcinoma & $1(2)$ & $0(0)$ & $2(3)$ & $62(95)$ & 98 & \\
\hline
\end{tabular}

PR, positive rate; $\mathrm{r}^{2}$, Spearman's Rank Correlation Coefficient.

Table IV. Correlation between BMP-9 and Ki-67 expression in colorectal cancer.

BMP-9 expression, $\mathrm{n}$

\begin{tabular}{lcccccccr}
\cline { 5 - 8 } Intensity of Ki-67 expression & & Number of patients, $n$ & - & + & ++ & +++ & $r^{2}$-value & P-value \\
\hline Ki-67 expression, $n$ & - & 1 & 0 & 0 & 1 & 0 & -0.024 \\
& + & 0 & 0 & 0 & 0 & 0 & 0.852 \\
& ++ & 2 & 0 & 0 & 1 & 1 & 24
\end{tabular}

BMP-9, bone morphogenetic protein-9; $\mathrm{r}^{2}$, Spearman's Coefficient of Rank Correlation.

2.9 and 1.4 , respectively; $\left.\mathrm{r}^{2}=0.711 ; \mathrm{P}<0.001\right)$. Interestingly, the Ki-67 index increased with more advanced cancer stages $\left(r^{2}=0.50 ; \mathrm{P}<0.001\right.$ adenoma vs. carcinoma; Table III). In addition, no correlation between BMP-9 and Ki-67 expression in CRC was observed $\left(r^{2}=-0.024 ; \mathrm{P}>0.05\right.$; Table IV).

Correlation between BMP-9 expression and the clinicopathological parameters of $C R C$. The expression of BMP-9 was significantly correlated with age $\left(\mathrm{r}^{2}=-0.329 ; \mathrm{P}=0.007\right)$, but not with other features, including sex, tumor location, gross tumor type, differentiation, histological type, WHO classification, blood vessel tumor emboli, TNM stage, and serum CEA and CA19-9 levels (Table V). In the Oncomine dataset, no significant association between BMP-9 mRNA and clinicopathological parameters was observed $(\mathrm{P}>0.05)$. In TCGA dataset, BMP-9 mRNA expression was not associated with the TNM stage (P>0.05; Fig. 2F-I). In the Kurashina dataset, BMP-9 expression was not associated with the grade classifications and Dukes stages ( $\mathrm{P}>0.05$; Fig. 2D and $\mathrm{E})$.

Survival analysis. In the follow-up period of $\geq 3$ years, the OS was $71 \%$; 14 patients had succumbed, including 2 patients who underwent a secondary operation. Of these 2 patients, one had undergone a secondary operation for an intestinal fistula observed 1 month after the initial procedure. The patient subsequently succumbed due to infectious peritonitis and septic shock. For the other patient, a secondary operation was conducted due to tumor relapse, which was identified 3 months after the initial procedure. The patient succumbed due to tumor progression and multiple organ metastasis 16 months after the primary surgery. Distant metastases were observed in 3 other patients; in the liver (after 11 months), the brain (after 25 months) and the bones (after 38 months), respectively. In addition, locoregional relapse was observed in 2 patients after 14 and 26 months, respectively.

In order to assess the association between the expression levels of BMP-9 and OS in colorectal carcinoma, BMP-9 expression was categorized into low- and high-expression groups according to the mean of their IHC scores. A total of 32 patients $(67 \%)$ had low BMP-9 expression levels, and 16 patients $(33 \%)$ exhibited high BMP-9 expression. Low BMP-9 expression was significantly associated with improved OS; the mean survival time for such patients was 56.4 months with a 95\% confidence interval (CI) of 50.8-62.0. On the contrary, high BMP-9 expression was associated with a mean survival time of 38.3 months with a $95 \%$ CI of $25.7-50.8$, whjch was significantly lower than the low-expression group ( $\mathrm{P}=0.009$; Table VI; Fig. 3).

In the univariate analyses, certain clinicopathological parameters, including tumor differentiation, WHO classification, blood vessel cancer embolus and TNM staging were significant predictors of a poor prognosis $(\mathrm{P}=0.035,0.035$, $<0.001$ and 0.022, respectively; Table VI). Sex, age, tumor location, gross tumor type, histological type, serum CEA and CA 19-9 levels were not associated with the prognosis of patients (all P>0.05; Table VI).

Furthermore, BMP-9 expression was independently associated with poor prognosis in $\mathrm{CRC}(\mathrm{P}=0.044)$ as determined by multivariate analyses, which indicated the prognostic significance of BMP-9 expression in CRC [hazard ratio (HR), 3.14; 95\% CI, 1.03-9.57; Table VII].

Bioinformatics analysis using the available datasets confirmed the observations that patients with CRC and high BMP-9 mRNA expression exhibited decreased OS time compared with those with low expression (Fig. 4A-L). 
Table V. Association between BMP-9 expression and the clinicopathological characteristics of patients with colorectal cancer.

\begin{tabular}{|c|c|c|c|c|c|c|c|}
\hline \multirow[b]{2}{*}{ Characteristics } & \multirow[b]{2}{*}{$\mathrm{n}$} & \multicolumn{4}{|c|}{ BMP-9 expression, $\mathrm{n}$} & \multirow[b]{2}{*}{$r^{2}$-value } & \multirow[b]{2}{*}{ P-value } \\
\hline & & - & + & ++ & +++ & & \\
\hline Sex & & & & & & -0.146 & 0.246 \\
\hline Male & 47 & 3 & 5 & 18 & 21 & & \\
\hline Female & 18 & 0 & 3 & 11 & 4 & & \\
\hline Age, years & & & & & & -0.329 & 0.007 \\
\hline$\leq 55$ & 11 & 0 & 0 & 3 & 8 & & \\
\hline$>55$ & 54 & 3 & 8 & 26 & 17 & & \\
\hline Site & & & & & & 0.048 & 0.703 \\
\hline Rectum & 39 & 2 & 6 & 18 & 13 & & \\
\hline Left-side colon & 17 & 1 & 1 & 7 & 8 & & \\
\hline Right-side colon & 9 & 0 & 1 & 4 & 4 & & \\
\hline Tumor gross type & & & & & & -0.067 & 0.596 \\
\hline Ulcerative type & 49 & 3 & 5 & 21 & 20 & & \\
\hline Elevated type & 16 & 0 & 3 & 8 & 5 & & \\
\hline Differentiation & & & & & & -0.175 & 0.164 \\
\hline Poor & 6 & 0 & 0 & 3 & 3 & & \\
\hline Moderate & 54 & 2 & 6 & 26 & 20 & & \\
\hline High & 5 & 1 & 2 & 0 & 2 & & \\
\hline Histological type & & & & & & -0.058 & 0.649 \\
\hline Tubular papillary & 16 & 1 & 0 & 10 & 5 & & \\
\hline Tubular & 44 & 1 & 6 & 19 & 18 & & \\
\hline Mucinous & 5 & 1 & 2 & 0 & 2 & & \\
\hline WHO classification & & & & & & -0.023 & 0.856 \\
\hline Low & 53 & 2 & 6 & 25 & 20 & & \\
\hline High & 12 & 1 & 2 & 4 & 5 & & \\
\hline Blood vessel tumor emboli & & & & & & -0.039 & 0.760 \\
\hline Positive & 7 & 0 & 1 & 3 & 3 & & \\
\hline Negative & 58 & 3 & 7 & 26 & 22 & & \\
\hline TNM stage & & & & & & -0.010 & 0.938 \\
\hline I-II & 46 & 2 & 6 & 20 & 18 & & \\
\hline III-IV & 19 & 1 & 2 & 9 & 7 & & \\
\hline Serum CEA levels & & & & & & -0.035 & 0.805 \\
\hline High & 22 & 2 & 3 & 7 & 10 & & \\
\hline Normal & 30 & 1 & 3 & 16 & 10 & & \\
\hline Serum CA19-9 levels & & & & & & -0.110 & 0.476 \\
\hline High & 9 & 0 & 1 & 4 & 4 & & \\
\hline Normal & 35 & 2 & 5 & 16 & 12 & & \\
\hline
\end{tabular}

BMP-9, bone morphogenetic protein-9; WHO, World Health Organization; TNM, Tumor-Node-Metastasis; CEA, carcinoembryonic antigen, CA19-9, carbohydrate antigen 19-9; $\mathrm{r}^{2}$, Spearman's Coefficient of Rank Correlation.

\section{Discussion}

BMP-9 belongs to the TGF- $\beta$ family and serves as a multifunctional mediator in numerous biological processes under physiological and pathophysiological conditions, particularly in tumorigenesis (10-19). The expression of BMP-9 and its tumorigenic and antitumorigenic roles notably varies according to the type of tumor $(22,23,25,28)$. To the best of our knowledge, the present study is the first to investigate the role of BMP-9 in the various stages of colorectal tumorigenesis, a process observed in the majority of types of colorectal tumor $(3,34,35)$, by analyzing matched normal mucosa, adenoma and carcinoma samples. The present study demonstrated that the expression of BMP-9 sequentially increased 
Table VI. Univariate analysis for BMP-9 expression and clinicopathological variables in patients with colorectal cancer.

\begin{tabular}{|c|c|c|c|c|}
\hline Characteristics & Number of patients, $n$ & Mean survival time, months & $95 \% \mathrm{CI}$ & P-value \\
\hline BMP-9 expression & & 50.485 & $44.330-56.640$ & 0.009 \\
\hline Low & 32 & 56.420 & $50.838-62.001$ & \\
\hline High & 16 & 38.250 & $25.675-50.825$ & \\
\hline Sex & & 50.485 & $44.330-56.640$ & 0.682 \\
\hline Male & 33 & 48.821 & $40.753-56.888$ & \\
\hline Female & 15 & 50.023 & $43.343-56.721$ & \\
\hline Age, years & & 50.485 & $44.330-56.640$ & 0.404 \\
\hline$\leq 55$ & 7 & 43.143 & 25.195-61.091 & \\
\hline$>55$ & 41 & 50.929 & $44.598-57.260$ & \\
\hline Tumor site & & 50.485 & $44.330-56.640$ & 0.066 \\
\hline Rectum & 28 & 53.415 & $46.560-60.270$ & \\
\hline Left-side colon & 14 & 47.071 & $36.059-58.083$ & \\
\hline Right-side colon & 6 & 31.833 & $13.128-50.539$ & \\
\hline Gross tumor type & & 50.485 & $44.330-56.640$ & 0.083 \\
\hline Ulcerative type & 37 & 46.533 & $39.125-53.941$ & \\
\hline Elevated type & 11 & 61.909 & $58.002-65.817$ & \\
\hline Differentiation & & 50.485 & $44.330-56.640$ & 0.035 \\
\hline Poor & 5 & 30.000 & $11.555-48.445$ & \\
\hline Moderate & 38 & 53.690 & $47.209-60.171$ & \\
\hline High & 5 & 41.400 & $26.588-56.212$ & \\
\hline Histological type & & 50.485 & $44.330-56.640$ & 0.353 \\
\hline Tubular papillary & 11 & 52.176 & $42.042-62.291$ & \\
\hline Tubular & 32 & 51.031 & $43.061-59.001$ & \\
\hline Mucinous & 5 & 41.400 & $26.588-56.212$ & \\
\hline WHO classification & & 50.485 & $44.330-56.640$ & 0.035 \\
\hline Low & 37 & 53.346 & $46.691-60.002$ & \\
\hline High & 11 & 39.818 & $26.680-52.956$ & \\
\hline Blood vessel tumor embolus & & 50.485 & $44.330-56.640$ & $<0.001$ \\
\hline Positive & 43 & 54.003 & $48.395-59.611$ & \\
\hline Negative & 5 & 16.000 & $4.046-27.954$ & \\
\hline TNM stage & & 50.485 & $44.330-56.640$ & 0.022 \\
\hline I-II & 32 & 54.088 & $47.489-60.686$ & \\
\hline III-IV & 16 & 41.193 & $29.813-52.572$ & \\
\hline Serum CEA levels & & 49.350 & $42.681-56.018$ & 0.185 \\
\hline High & 21 & 54.420 & $44.365-56.475$ & \\
\hline Normal & 18 & 44.222 & $32.885-55.559$ & \\
\hline Serum CA19-9 levels & & 45.344 & $38.817-51.871$ & 0.073 \\
\hline High & 26 & 48.793 & $42.597-54.990$ & \\
\hline Normal & 7 & 32.429 & $15.235-49.622$ & \\
\hline
\end{tabular}

BMP-9, bone morphogenetic protein-9; CI, confidence interval; WHO, World Health Organization; TNM, Tumor-Node-Metastasis; CEA, carcinoembryonic antigen; CA19-9, carbohydrate antigen 19-9.

in normal mucosa, adenoma and carcinoma. These results suggested that BMP-9 may be an important protumorigenic factor in the development of CRC. In addition, it was revealed that BMP-9 may serve as an independent prognostic factor for patients with CRC, and that high BMP-9 expression was significantly associated with poor prognosis and decreased survival rate.
BMP-9 was first detected in fetal mouse liver, and it can bind to activin receptor-like kinase 1 , a TGF family type 1 receptor, to serve an important role in angiogenesis $(10,19)$. It is well known that angiogenesis is a critical process in tumorigenesis (36). Recently, Na et al (20) reported that BMP-9 was upregulated in papillary thyroid carcinoma compared with normal follicular cells $(\mathrm{P}<0.001)$, regardless of 


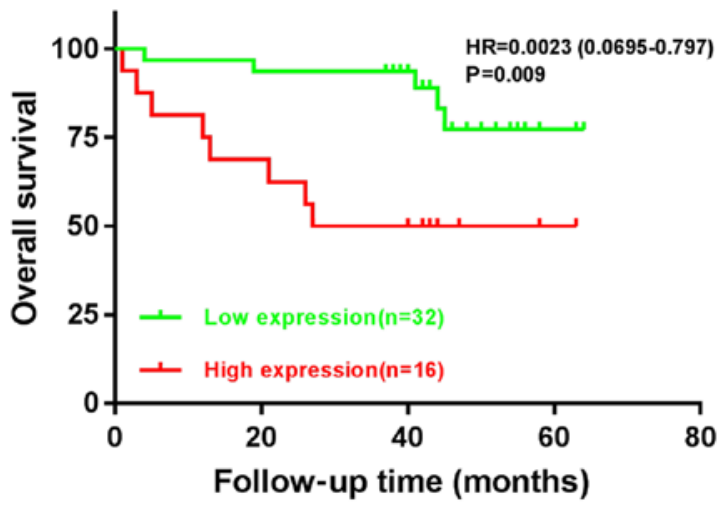

Figure 3. Overall survival rate of patients with colorectal cancer with varying expression levels of BMP-9. Red and green indicate high (IHC scores: >2) and low expression (IHC scores: $\leq 2$ ), respectively. HR, hazard ratio.

bone formation. Similarly, Herrera et al (21) detected BMP-9 expression in epithelial ovarian cancer cells, but not in normal human ovarian surface epithelial cells. The results of the present study suggested an increase in BMP-9 expression with advancing stages of colorectal tumorigenesis. Conversely, Ren et al (27) revealed that BMP-9 may function as a tumor suppressor in breast cancer cells in vitro and in vivo. A similar role was also reported for BMP-9 in prostate cancer $(24,37)$, osteosarcoma (38) and myeloma (25). These discrepancies require further investigation; however, they indicate that the role of BMP-9 may be tissue- and tumor-specific.

BMP signaling has been investigated in the development of colorectal carcinogenesis (39-41). Although research has been performed following the detection of a germline mutation of bone morphogenetic protein receptor type $1 \mathrm{~A}$ in patients with juvenile polyposis syndrome, the precise role of BMP signaling in CRC remains unclear $(42,43)$. BMP-2 and BMP-3 were determined to have growth-suppressive activities in colon cancer cells $(8,44)$. However, Yokoyama et al $(6)$ reported that the expression levels of BMP-4 in human CRC cells and tissues were upregulated when compared with those in normal epithelium or adenoma, while inhibition of BMP-4 promoted the apoptosis of CRC cells in vitro and in vivo. These findings were consistent with the reports of the present study. Furthermore, Yuan et al (45) demonstrated that BMP-9 was essential for the antiproliferative effects of resveratrol on human colon cancer. Conversely, Lorente-Trigos et al (46) revealed that BMP signaling promoted the growth of primary human colon carcinomas in vivo. Whether the inconsistency in these reports is due to context differences or cross-talk involving other signaling pathways in colorectal tumorigenesis at different stages requires further investigation.

Notably, in the present study, the expression of BMP-9 gradually increased within the cytoplasm or/and membrane in tissues of advancing tumor stages, from normal colorectal mucosa to adenoma and carcinoma. This suggested a potential role of high cytoplasmic or membranous BMP-9 expression in colorectal tumorigenesis. Similarly, an increase of galectin 3 in the cytoplasm has been associated with the progression of CRC (47). Miyata et al (48) also observed a similar correlation between the enhanced expression of ELAV like RNA binding protein 1 in the cytoplasm, and the aggressiveness and poor
Table VII. Multivariate Cox regression analysis for overall survival in patients with colorectal cancer.

\begin{tabular}{lclc}
\hline Characteristics & HR & \multicolumn{1}{c}{$95 \%$ CI } & P-value \\
\hline BMP-9 expression & 3.143 & $1.032-9.571$ & 0.044 \\
Differentiation & 1.021 & $0.435-2.395$ & 0.962 \\
WHO classification & 1.044 & $0.232-4.705$ & 0.955 \\
Blood vessel tumor embolus & 5.142 & $0.866-30.315$ & 0.072 \\
TNM stage & 1.896 & $0.506-7.103$ & 0.343 \\
\hline
\end{tabular}

HR, hazard ratio; CI, confidence interval; BMP-9, bone morphogenetic protein-9; WHO, World Health Organization.

prognosis of bladder cancer. However, due to the limitations of IHC staining in the present study, the correlation between the cytoplasmic expression of BMP-9 and poor prognosis in patients with CRC could not be assessed.

In order to evaluate the prognostic value of BMP-9 expression in patients with CRC, a Kaplan-Meier univariate survival analysis was performed in the present study, which revealed an association between high BMP-9 expression levels and poor prognosis in patients with this disease. When the Cox proportional hazards model was generated, high BMP-9 expression levels were determined to be an independent factor for predicting the unfavorable prognosis of patients with CRC. These results suggested that BMP-9 may be a prognostic marker for patients with this disease.

Numerous proteins or genes identified thus far have been used as prognostic biomarkers for various types of CRC (49,50); however, improvements are required. Considering the results from the present study, BMP-9 may be a valuable addition to the clinical management of patients with CRC and could contribute to the improvement of treatment outcomes.

An increasing number of studies have focused on BMP-9 as a therapeutic target for the treatment of cancer, particularly tumor angiogenesis $(51,52)$. In light of the results from the present study, the development of a novel therapeutic strategy targeting BMP-9 in CRC is warranted.

The primary limitation of the present study was the evaluation of BMP-9 expression using IHC staining. The semi-quantitative nature of this analysis may have negatively influenced its statistical power. Therefore, reverse transcription-quantitative PCR should be performed in order to confirm the results of the present study, along with a more thorough correlation analysis. Furthermore, other limitations included the small sample size employed, and the lack recurrence-free and disease-free survival data.

The findings of the present study suggested that increased BMP-9 expression may serve an important role in promoting colorectal tumorigenesis by driving the transformation of colorectal normal mucosa to adenoma, and subsequent carcinoma. In addition, upregulated BMP-9 levels may be an independent predictor of poor prognosis for patients with CRC. Thus, modulating BMP-9 activity may be considered as a novel therapeutic strategy in the treatment of CRC; however, further investigation is warranted to elucidate the mechanism underlying the protumorigenic effects of BMP-9 in the disease. 

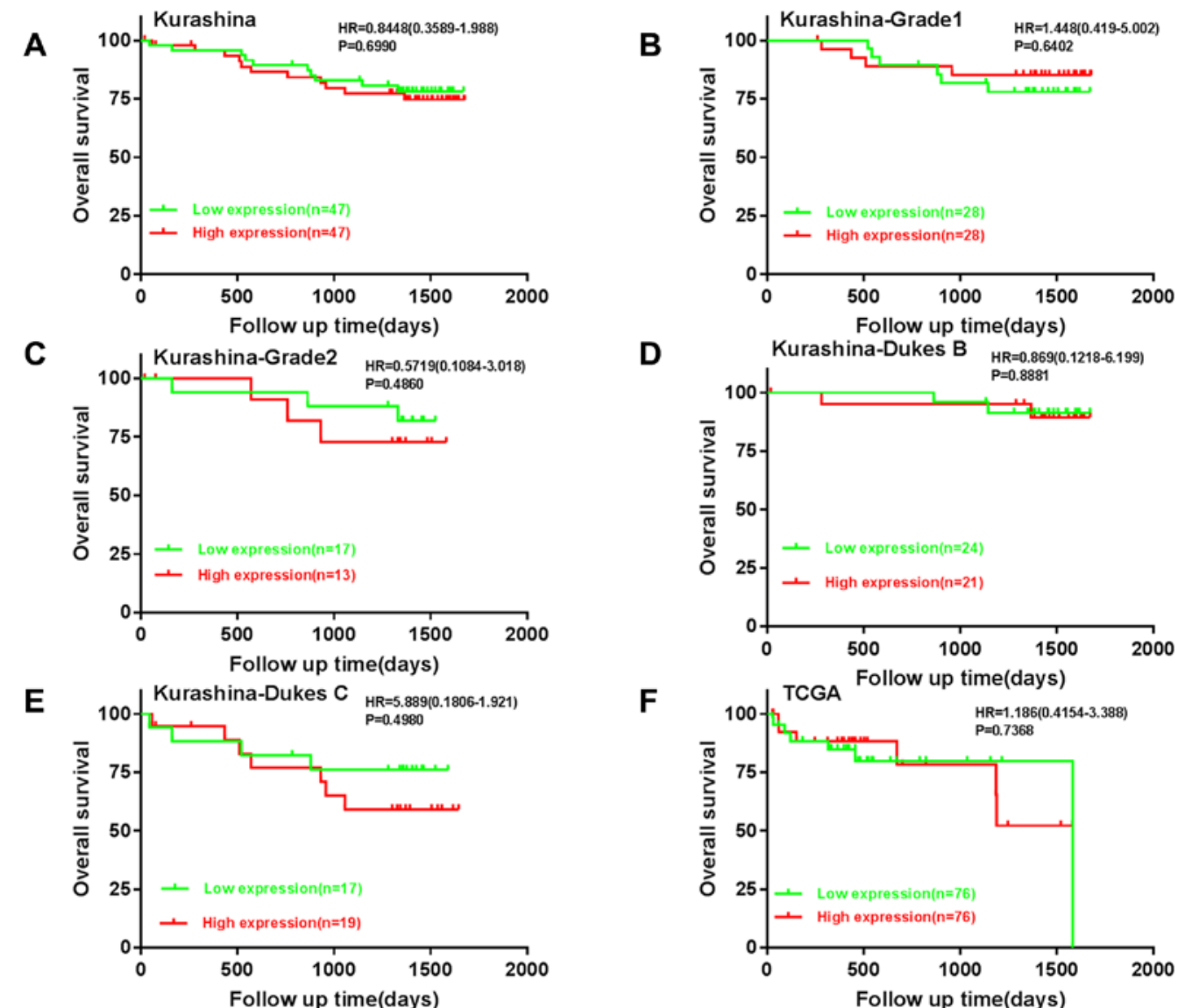

$\mathbf{F}$
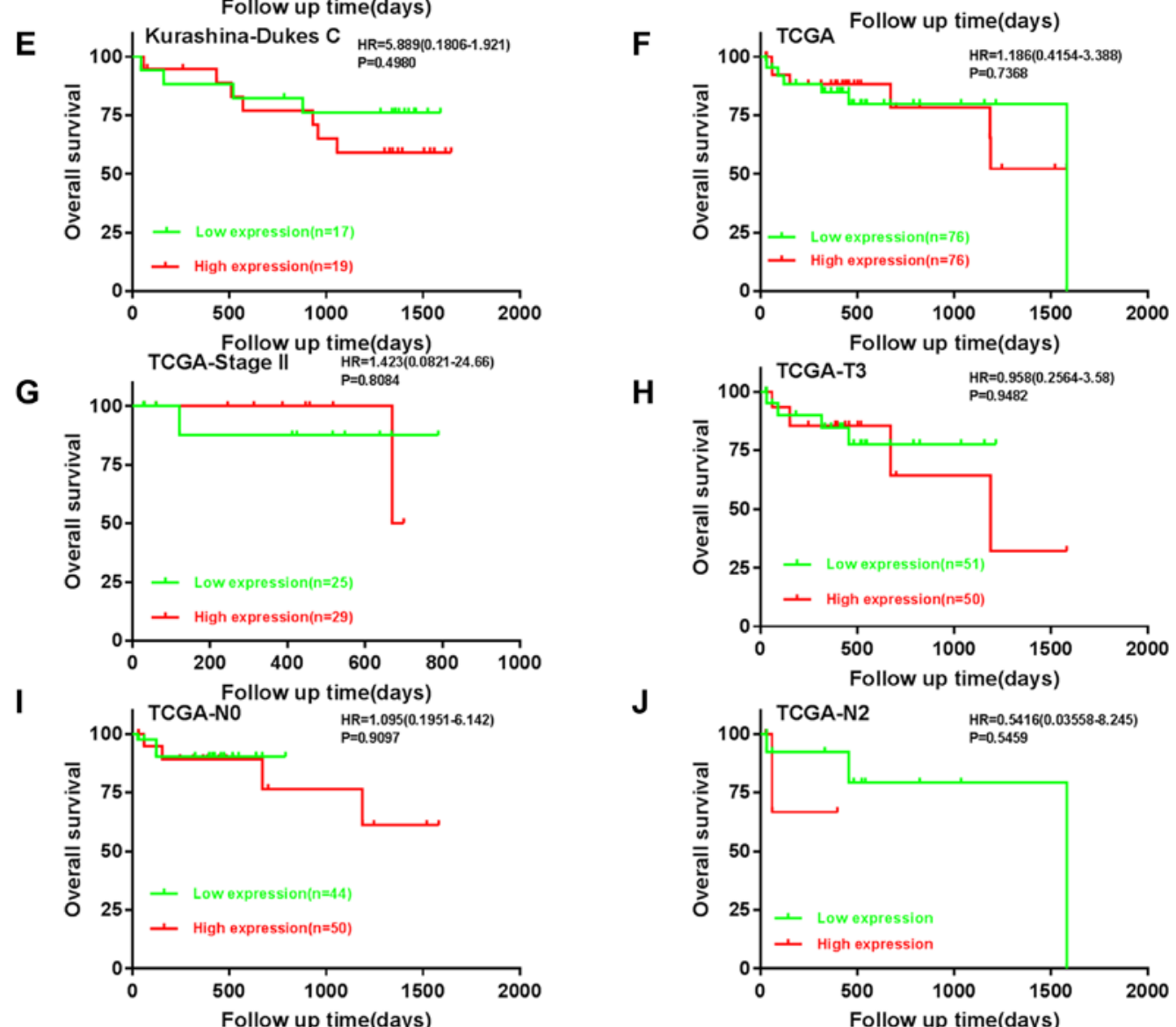

$\mathbf{J}$
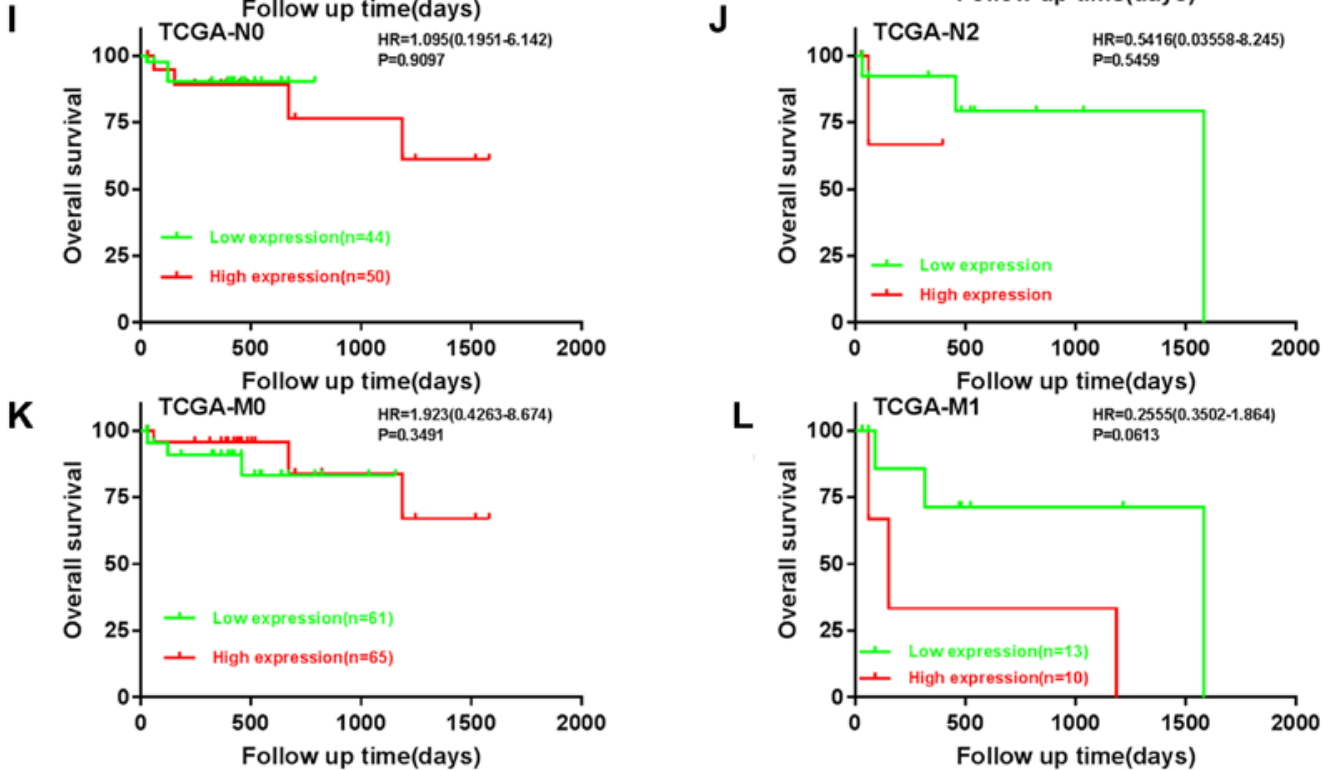

Figure 4. Prognostic value of BMP-9 expression in CRC. The TCGA (mRNA) and Kurashina (DNA) datasets were used to analyze the prognostic value of BMP-9 in colorectal carcinogenesis. Analysis of The Cancer Genome Atlas and Kurashina datasets revealed that BMP-9 mRNA expression was not associated with the overall survival rates of patients with CRC in (A) Kurashina and (F) TCGA datasets, regardless of subsequent analysis that stratified patients into the following subgroups: (B) Grade 1; (C) grade 2; (D) Dukes stage B; (E) Dukes stage C; (G) stage II; (H) T3; (I) N0; (J) N2; (K) M0; and (L) M1. BMP-9, bone morphogenetic protein-9; CRC, colorectal cancer; HR, hazard ratio; TCGA, The Cancer Genome Atlas; T, tumor; N, node; M, metastasis. 


\section{Acknowledgements}

Not applicable.

\section{Funding}

No funding was received.

\section{Availability of data and materials}

The datasets generated and/or analyzed during the present study are available from the Oncomine and TCGA databases: oncomine.org/;ncbi.nlm.nih.gov/geo/query/acc.cgi?acc=GSE11417; ncbi.nlm.nih.gov/geo/query/acc.cgi?acc=GSE20842; and cancergenome.nih.gov/.

\section{Authors' contributions}

HS and HZ designed the study. YF designed the study and wrote the manuscript. YF and WW collected the data. YF, LG and WW performed the experiments. YF and CJ analyzed the data. All authors read and approved the final manuscript. All authors read and approved the final manuscript.

\section{Ethics approval and consent to participate}

This study was approved by the Ethics Committee of the First Affiliated Hospital of Jinzhou Medical University (Jinzhou, China). The Ethics Committee waived the need for written informed consent due to the retrospective nature of the study.

\section{Patient consent for publication}

Not applicable.

\section{Competing interests}

The authors declare that they have no competing interests.

\section{References}

1. Siegel RL, Miller KD and Jemal A: Cancer statistics, 2019. CA Cancer J Clin 69: 7-34, 2019.

2. Siegel RL, Miller KD, Fedewa SA, Ahnen DJ, Meester RGS, Barzi A and Jemal A: Colorectal cancer statistics, 2017. CA Cancer J Clin 67: 177-193, 2017.

3. Fearon ER and Vogelstein B: A genetic model for colorectal tumorigenesis. Cell 61: 759-767, 1990.

4. Vincent MD: Cancer: Beyond speciation. Adv Cancer Res 112: 283-350, 2011.

5. Terzić J, Grivennikov S, Karin E and Karin M: Inflammation and colon cancer. Gastroenterology 138: 2101-2114, 2010.

6. Yokoyama Y, Watanabe T, Tamura Y, Hashizume Y, Miyazono K and Ehata S: Autocrine BMP-4 signaling is a therapeutic target in colorectal cancer. Cancer Res 77: 4026-4038, 2017.

7. Miyazono K, Kamiya Y and Morikawa M: Bone morphogenetic protein receptors and signal transduction. J Biochem 147: 35-51, 2010.

8. Zhang Y, Chen X, Qiao M, Zhang BQ, Wang N, Zhang Z, Liao Z, Zeng L, Deng Y, Deng F, et al: Bone morphogenetic protein 2 inhibits the proliferation and growth of human colorectal cancer cells. Oncol Rep 32: 1013-1020, 2014.

9. Chen D, Zhao M, Harris SE and Mi Z: Signal transduction and biological functions of bone morphogenetic proteins. Front Biosci 9: 349-358, 2004.
10. Celeste AJ: Bone morphogenetic protein-9, a new member of the TGF- $\beta$ superfamily. J Bone Miner Res 1 9: S136, 1994.

11. Wagner DO, Sieber C, Bhushan R, Börgermann JH, Graf D and Knaus P: BMPs: From bone to body morphogenetic proteins. Sci Signal 3: mr1, 2010.

12. Plouhinec JL, Zakin L and De Robertis EM: Systems control of BMP morphogen flow in vertebrate embryos. Curr Opin Genet Dev 21: 696-703, 2011.

13. Reddi AH and Reddi A: Bone morphogenetic proteins (BMPs): From morphogens to metabologens. Cytokine Growth Factor Rev 20: 341-342, 2009.

14. Ploemacher RE, Engels LJ, Mayen AE, Thies S and Neben S: Bone morphogenetic protein 9 is a potent synergistic factor for murine hemopoietic progenitor cell generation and colony formation in serum-free cultures. Leukemia 13: 428-437, 1999.

15. Helm GA, Alden TD, Beres EJ, Hudson SB, Das S, Engh JA, Pittman DD, Kerns KM and Kallmes DF: Use of bone morphogenetic protein-9 gene therapy to induce spinal arthrodesis in the rodent. J Neurosurg 92 (Suppl): S191-S196, 2000.

16. Lopez-Coviella I, Berse B, Krauss R, Thies RS and Blusztajn JK: Induction and maintenance of the neuronal cholinergic phenotype in the central nervous system by BMP-9. Science 28: 313-316, 2000.

17. Chen C, Grzegorzewski KJ, Barash S, Zhao Q, Schneider H, Wang Q, Singh M, Pukac L, Bell AC, Duan R, et al: An integrated functionalgenomics screening program reveals a role for BMP-9 in glucose homeostasis. Nat Biotechnol 21: 294-301, 2003.

18. Truksa J, Peng HF, Lee P and Beutler E: Bone morphogenetic proteins 2, 4, and 9 stimulate murine hepcidin 1 expression independently of Hfe, transferrin receptor 2 (Tfr2), and IL-6. Proc Natl Acad Sci USA 103: 10289-10293, 2006.

19. David L, Mallet C, Mazerbourg S, Feige JJ and Bailly S: Identification of BMP9 and BMP10 as functional activators of the orphan activin receptor-like kinase 1 (ALK1) in endothelial cells. Blood 109: 1953-1961, 2007.

20. Na KY, Kim HS, Lee SK, Jung WW, Sung JY, Kim YW and Park YK: Papillary thyroid carcinoma with bone formation. Pathol Res Pract 209: 14-18, 2013.

21. Herrera B, van Dinther M, Ten Dijke P and Inman GJ: Autocrine bone morphogenetic protein-9 signals through activin receptor-like kinase-2/Smad1/Smad4 to promote ovarian cancer cell proliferation. Cancer Res 69: 9254-9262, 2009.

22. Herrera B, García-Álvaro M, Cruz S, Walsh P, Fernández M, Roncero C, Fabregat I, Sánchez A and Inman GJ: BMP9 is a proliferative and survival factor for human hepatocellular carcinoma cells. PLoS One 8: e69535, 2013.

23. Li Q, Gu X, Weng H, Ghafoory S, Liu Y, Feng T, Dzieran J, Li L, Ilkavets I and Kruithof-de Julio M: Bone morphogenetic protein-9 induces epithelial to mesenchymal transition in hepatocellular carcinoma cells. Cancer Sci 104: 398-408, 2013.

24. Ye L, Kynaston $\mathrm{H}$ and Jiang WG: Bone morphogenetic protein-9 induces apoptosis in prostate cancer cells, the role of prostate apoptosis response-4. Mol Cancer Res 6: 1594-1606, 2008.

25. Olsen OE, Wader KF, Misund K, Våtsveen TK, Rø TB, Mylin AK, Turesson I, Størdal BF, Moen SH, Standal T, et al: Bone morphogenetic protein-9 suppresses growth of myeloma cells by signaling through ALK2 but is inhibited by endoglin. Blood Cancer J 4: e196, 2014.

26. Wan S, Liu Y, Weng Y, Wang W, Ren W, Fei C, Chen Y, Zhang Z, Wang T, Wang J, et al: BMP9 regulates cross-talk between breast cancer cells and bone marrow-derived mesenchymal stem cells. Cell Oncol (Dordr) 37: 363-375, 2014.

27. Ren W, Liu Y, Wan S, Fei C, Wang W, Chen Y, Zhang Z, Wang T, Wang J, Zhou L, et al: BMP9 inhibits proliferation and metastasis of HER2-positive SK-BR-3 breast cancer cells through ERK1/2 and PI3K/AKT pathways. PLoS One 9: e96816, 2014.

28. Ren W, Sun X, Wang K, Feng H, Liu Y, Fei C, Wan S, Wang W, Luo J, Shi Q, et al: BMP9 inhibits the bone metastasis of breast cancer cells by downregulating CCN2 (connective tissue growth factor, CTGF) expression. Mol Biol Rep 41: 1373-1383, 2014.

29. America Joint Committee on Cancer. The 7th edition of the AJCC cancer staging manual. 7th ed. New York: Springer, 2010.

30. Edge SB and Compton CC: The American joint committee on cancer: The 7th edition of the AJCC cancer staging manual and the future of TNM. Ann Surg Oncol 17: 1471-1474, 2010.

31. Sarma DP: Dukes' classification of rectal cancer. South Med J 81: 407-408, 1988 
32. Kurashina K, Yamashita Y, Ueno T, Koinuma K, Ohashi J, Horie H, Miyakura Y, Hamada T, Haruta H, Hatanaka $\mathrm{H}$, et al: Chromosome copy number analysis in screening for prognosisrelated genomic regions in colorectal carcinoma. Cancer Sci 99: 1835-1840, 2008.

33. Gaedcke J, Grade M, Jung K, Camps J, Jo P, Emons G, Gehoff A, Sax U, Schirmer M, Becker H, et al: Mutated KRAS results in overexpression of DUSP4, a MAP-kinase phosphatase, and SMYD3, a histone methyltransferase, in rectal carcinomas. Genes Chromosomes Cancer 49: 1024-1034, 2010.

34. Muto T, Bussey HJ and Morson BC: The evolution of cancer of the colon and rectum. Cancer 36: 2251-2270, 1975.

35. Kinzler KW and Vogelstein B: Lessons from hereditary colorectal cancer. Cell 87: 159-170, 1996.

36. Herrera B, Dooley S and Breitkopf-Heinlein K: Potential roles of bone morphogenetic protein (BMP)-9 in human liver diseases. Int J Mol Sci 15: 5199-5220, 2014.

37. Astrologo L, Zoni E, Karkampouna S, Gray PC, Klima I, Grosjean J, Goumans MJ, Hawinkels LJAC, van der Pluijm G, Spahn M, et al: ALK1Fc Suppresses the human prostate cancer growth in in vitro and in vivo preclinical models. Front Cell Dev Biol 5: 104, 2017.

38. Lv Z, Yang D, Li J, Hu M, Luo M, Zhan X, Song P, Liu C, Bai H, $\mathrm{Li} \mathrm{B}$, et al: Bone morphogenetic protein 9 overexpression reduces osteosarcoma cell migration and invasion. Mol Cells 36: 119-126, 2013.

39. Hardwick JC, Kodach LL, Offerhaus GJ and van den Brink GR Bone morphogenetic protein signalling in colorectal cancer. Nat Rev Cancer 8: 806-812, 2008.

40. Allaire JM, Roy SA, Ouellet C, Lemieux É, Jones C, Paquet M, Boudreau $\mathrm{F}$ and Perreault $\mathrm{N}$ : Bmp signaling in colonic mesenchyme regulates stromal microenvironment and protects from polyposis initiation. Int J Cancer 138: 2700-2712, 2016.

41. Voorneveld PW, Kodach LL, Jacobs RJ, van Noesel CJ, Peppelenbosch MP, Korkmaz KS, Molendijk I, Dekker E, Morreau H, van Pelt GW, et al: The BMP pathway either enhances or inhibits the Wnt pathway depending on the SMAD4 and p53 status in CRC. Br J Cancer 112: 122-130, 2015.

42. Howe JR,BairJL,Sayed MG, Anderson ME, Mitros FA, Petersen GM, Velculescu VE, Traverso G and Vogelstein B: Germline mutations of the gene encoding bone morphogenetic protein receptor $1 \mathrm{~A}$ in juvenile polyposis. Nat Genet 28: 184-187, 2001.

43. Davis H, Raja E, Miyazono K, Tsubakihara Y and Moustakas A Mechanisms of action of bone morphogenetic proteins in cancer. Cytokine Growth Factor Rev 27: 81-92, 2016.
44. Loh K, Chia JA, Greco S, Cozzi SJ, Buttenshaw RL, Bond CE, Simms LA, Pike T, Young JP, Jass JR, et al: Bone morphogenetic protein 3 inactivation is an early and frequent event in colorectal cancer development. Genes Chromosomes Cancer 47: 449-460, 2008.

45. Yuan SX, Wang DX, Wu QX, Ren CM, Li Y, Chen QZ, Zeng YH, Shao Y, Yang JQ, Bai Y, et al: BMP9/p38 MAPK is essential for the antiproliferative effect of resveratrol on human colon cancer. Oncol Rep 35: 939-947, 2016.

46. Lorente-Trigos A, Varnat F, Melotti A and Ruiz I Altaba A: BMP signaling promotes the growth of primary human colon carcinomas in vivo. J Mol Cell Biol 2: 318-332, 2010.

47. Sanjuan X, Fernández PL, Castells A, Castronovo V, van den Brule F, Liu FT, Cardesa A and Campo E: Differential expression of galectin 3 and galectin 1 in colorectal cancer progression. Gastroenterology 113: 1906-1915, 1997.

48. Miyata Y, Watanabe S, Sagara Y, Mitsunari K, Matsuo T, Ohba K and Sakai H: High expression of HuR in cytoplasm, but not nuclei, is associated with malignant aggressiveness and prognosis in bladder cancer. PLoS One 8: e59095, 2013.

49. Steinke-Lange V and Holinski-Feder E: Genetic screening and personalized prevention in colorectal cancer. Visc Med 35: 226-230, 2019.

50. De Roock W, De Vriendt V, Normanno N, Ciardiello F and Tejpar S: KRAS, BRAF, PIK3CA, and PTEN mutations: Implications for targeted therapies in metastatic colorectal cancer. Lancet Oncol 12: 594-603, 2011.

51. Yoshimatsu Y, Lee YG, Akatsu Y, Taguchi L, Suzuki HI, Cunha SI, Maruyama K, Suzuki Y, Yamazaki T, Katsura A, et al: Bone morphogenetic protein-9 inhibits lymphatic vessel formation via activin receptor-like kinase 1 during development and cancer progression. Proc Natl Acad Sci USA 110: 18940-18945, 2013.

52. Cunha SI and Pietras K: ALK1 as an emerging target for antiangiogenic therapy of cancer. Blood 117: 6999-7006, 2011.

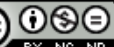

This work is licensed under a Creative Commons Attribution-NonCommercial-NoDerivatives 4.0 International (CC BY-NC-ND 4.0) License. 